\section{God in the details}

Jerry A. Coyne

Darwin's Black Box: The Biochemical Challenge to Evolution. By Michael J. Behe. Free Press/Simon and Schuster: 1996. Pp. 307. \$25.

THE goal of creationists has always been to replace the teaching of evolution with the narrative given in the first eleven chapters of Genesis. When the courts stymied this effort, creationists tried a new strategy: cloaking themselves in the mantle of science. This produced the oxymoronic 'scientific creationism', arguing that the very facts of biology and geology show that the Earth is young, all species were created suddenly and simultaneously, and mass extinctions were caused by a great worldwide flood. The resemblance between this theory and the book of Genesis was, of course, purely coincidental. Scientific creationism, however, also came to grief. Virtually all creation 'scientists' were religious fundamentalists without biological expertise, and American courts clearly spied clerical collars beneath the lab coats.

In Darwin's Black Box, Michael Behe offers a new and more sophisticated version of scientific creationism. Unlike his predecessors, Behe is a genuine scientist, a biochemist from Lehigh University in Pennsylvania. The book jacket asserts that he is not a creationist, but believes in the scientific method. His argument, however, is a recycled version of the creationist notion that 'complex design' implies an intelligent designer. But where William Paley illustrated this logic with a watch, Behe uses biochemistry. His intended audience of lay readers may be impressed by the elaborate descriptions of molecular biology and long lists of references, but Behe's 'scientific' alternative to evolution ultimately becomes a confusing and untestable farrago of contradictory ideas.

Behe's thesis is that organisms harbour molecular pathways so elaborate and interconnected that they cannot be explained by gradual evolution from simpler precursors. His examples of such pathways, described with admirable clarity, include blood-clotting, the immune system and intracellular transport. These share what he calls "irreducible complexity": they would not function if any single component were removed. Because Darwinism requires that a pathway be useful at every stage of its evolution, Behe claims that such irreducibly complex pathways could not evolve in steps. Their existence therefore implies conscious design and an intelligent designer. (Like all scientific creationists, Behe keeps quiet about the identity of the Great Designer, but the author's professed Roman Catholicism offers one clue.) Evo- lutionists are said to resist this idea of design because of our dogged but unreasonable dislike of supernatural explanations. Behe, however, is free from this constraint. With paternal pride, he declares that his discovery of biochemical design "must be ranked as one of the greatest achievements in the history of science", rivalling "those of Newton and Einstein, Lavoisier and Schrödinger, Pasteur, and Darwin".

There is no doubt that the pathways described by Behe are dauntingly complex, and their evolution will be hard to unravel. Unlike anatomical structures, the evolution of which can be traced with fossils, biochemical evolution must be reconstructed from highly evolved living organisms, and we may forever be unable to envisage the first proto-pathways. It is not valid, however, to assume that, because one man cannot imagine such pathways, they could not have existed. Moreover, as J. B. S. Haldane pointed out: "My own suspicion is that the universe is not only queerer than we suppose, but queerer than we can suppose." We face not only an absence of data, but also the awful fact that we ourselves are evolved creatures with limited cognition and imagination.

The answer to Behe's argument lies in realizing that biochemical pathways did not evolve by the sequential addition of steps to pathways that became functional only at the end. Instead, they have been rigged up with pieces co-opted from other pathways, duplicated genes and early multifunctional enzymes. Thrombin, for example, is one of the key proteins in blood-clotting, but also acts in cell division, and is related to the digestive enzyme trypsin. Who knows which function came first? Behe makes a few half-hearted attempts to build up such pathways, but quickly abandons the enterprise and cries "design".

Evolutionists will find two other problems with Behe's arguments. First, there is ample evidence for the evolution of morphology and anatomy from studies of palaeontology, embryology, biogeography and vestigial organs. Such evolution must, of course, be based on the evolution of molecules and biochemical pathways. Second, we have plenty of direct evidence for the evolution of molecules. This includes the remarkable congruence between phylogenies based on anatomy and those based on DNA or protein sequence (bat haemoglobin, for example, is far more similar to that of whales than of birds), the relatedness of genes through gene duplication (including those involved in the immune system and blood-clotting), and the existence of vestigial 'pseudogenes' that were useful in ancestors. (Unlike most mammals, humans cannot synthesize vitamin $C$; we still carry the gene for the final step in this pathway, but deletions have rendered it non-functional.)

Behe's response to these problems constitutes the major weakness of his theory. $\mathrm{He}$ chews on the idea of morphological evolution, but cannot bring himself to swallow it. He finds the idea of common descent of all organisms "fairly convincing", and admits that microevolution occurs within species, but sees no evidence for transitions between major forms. (How one can admit common descent but deny

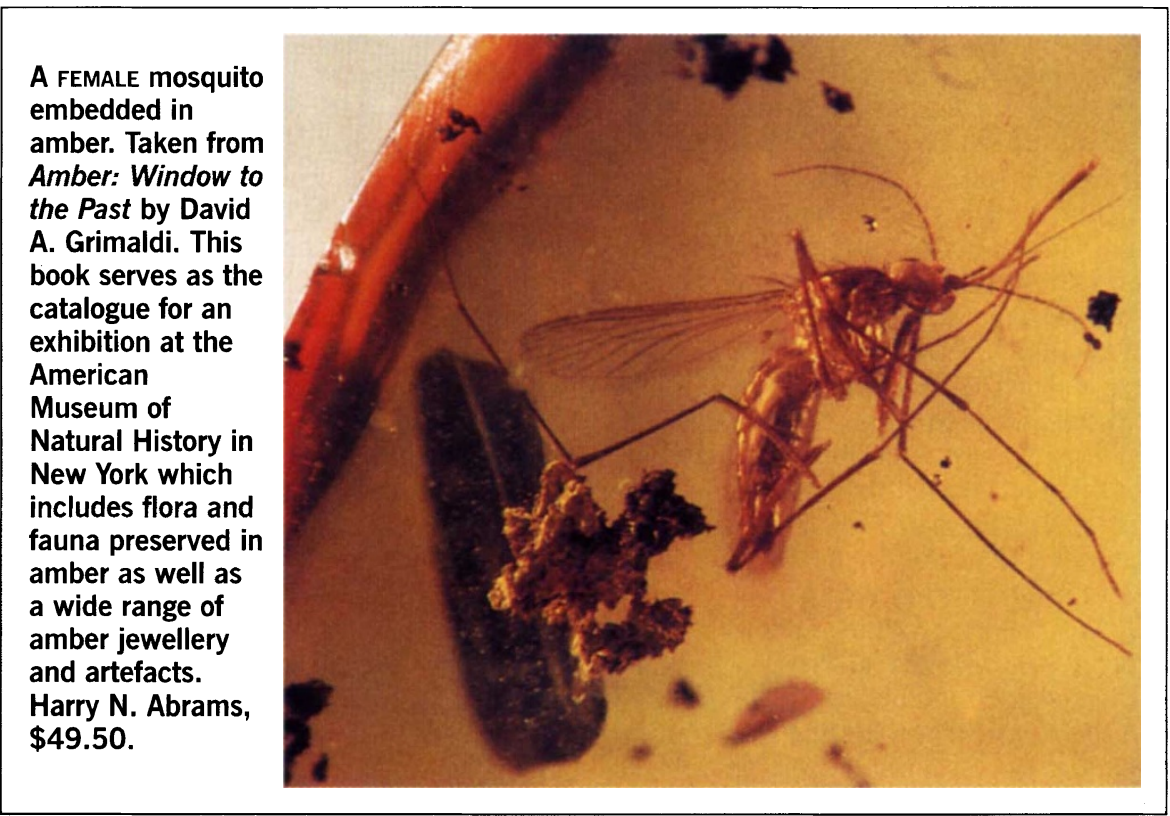

